\title{
STUDIES OF 2-[5-(ARYLOXYMETHYL)-1, 3, 4-OXADIAZOL- 2-YLSULFANYL] ACETIC ACID DERIVATIVES FOR ANTI- BACTERIAL ACTIVITIES VIA DFT, QSAR AND DOCKING APPROACHES
}

\author{
Abel Kolawole Oyebamiji* and Banjo Semire \\ Department of Pure and Applied Chemistry, Faculty of Pure and Applied Sciences, Ladoke Akintola \\ University of Technology, Ogbomoso, Oyo State, Nigeria \\ *E-mail: abeloyebamiji@gmail.com \\ Tel.: +2348032493676.
}

Received: Nov 01, 2017 / Revised: Nov 29, 2017 / Accepted: Nov 30, 2017

\begin{abstract}
The inhibitory activity of 2-[5-(aryloxymethyl)-1, 3, 4-oxadiazol-2-ylsulfanyl] acetic acid derivatives were considered and used against $S$. aureus cell line using density functional theory (DFT), quantitative structure activity relationship (QSAR) and docking methods. In this paper, many parameters (HOMO, LUMO, Log P, Molecular weight, dipole moment, chemical hardness, chemical potential and solvation energy) obtained via DFT method disclosed that each parameters obtained has a balanced connection with experimental anti-bacterial activity. Moreover, the predicted bioactivity $\left(I C_{50}\right)$ agreed well with the observed $I C_{50}$ using the developed QSAR model. More so, the studied compounds were docked against $S$. aureus cell line $(4 \mathrm{~b} 19)$ and the binding energy obtained from ligand-receptor.
\end{abstract}

Key words: Oxadiazole analogs, Acetic acid derivatives, DFT, QSAR, Molecular docking.

\section{INTRODUCTION}

One of the primogenital and most copious being formed in the globe is bacteria and their phages. They are advantageous for well-being of human; therefore, they live together with human being (Backhed et al 2005; Fauci et al 2005; Kaiser, 2005). Bacteria are very insignificant to be hold with the unassisted eye and are categorized by prokaryotic cellular organization. More so, the presence of bacteria in the body is much more than normal human-cells, thus, they are necessary for apt improvement, sustenance, and opposition to malady (Maloy and Schaechter, 2006; Overbye and Barrett, 2005).

Acetic acid is the molecular compound with uniqueness aroma and acerbic taste of vinegar. Several derivatives of acetic acid are very useful in the production of industrial chemicals, pharmaceuticals (NSAIDS), perfumes, plastics, synthetic fibers, explosives, antifungals and weed killers (Brogden, 1986; Dahiya and Kaur, 2007; Dahiya and Mourya, 2012; Dahiya et al 2006a; 2006b; 2008).

Furthermore, the global use of density functional theory in the study of molecular compounds with anti-bacterial activities by scientists is at its highest level (Oyebamiji and Semire, 2016a). This is due to it highly momentous role played in explicating the electronic structure and reactivity of compounds (Kraka and Cremer, 2000). However, computational chemistry comprise of other methods, but the efficient building of new measure for justifying, predicting and understanding chemical processes made density functional theory stand out technique (Jacquemin et al 2009). Now, 
quantum chemical calculation via density functional theory helped to recognize the antibacterial activities of descriptors by linking the observed facts to calculated molecular descriptors like HOMO energy, LUMO energy, band gap energy, dipole moment, charges on every heteroatoms etc. (Hansch, 1969; Ramsden, 1990).

Quantitative Structural Activity Relationship (QSAR) as an algebraic model that embroils the association between physicochemical descriptors of a ligand to its biological doings (Oyebamiji and Semire, 2016b). In bulk system, toxicity of substance is predicted with the aid of quantitative structural activity relationship and also helps in the case of classic chemicals (Dahl et al 2014; Oyebamiji and Semire, 2016c). The use of calculated molecular parameters obtained from quantum chemical methods (QCM) for building QSAR models has been described to be adequate for generating ample QSAR. Therefore, the use of quantum chemical descriptors has great importance (Arulmozhiraja and Morita, 2004; Gu et al 2009; Eroglu and Turkmen, 2007; Zhu et al 2010).

In molecular biology and computer-based drug device, docking as an emergent device is essential (Sharma et al 2011; Balasubramanian and Vijaya Gopal, 2012; Sharma and Kumar, 2014). It can also be used to do practical selection on vast set of molecules and scoring as well as divulging the steps involved in prevention of target binding site by ligands. Therefore, the calculations of interaction energy can be shown in form of "dock score" (Morris and Lim-Wilby, 2008).

Therefore, in present study, seven compounds (Figure 1) synthesized and screened against S. aureus, were optimized via density functional theory method so as to obtain molecular descriptors and used by calculating virtual screening and binding energy (Jain et al 2016).

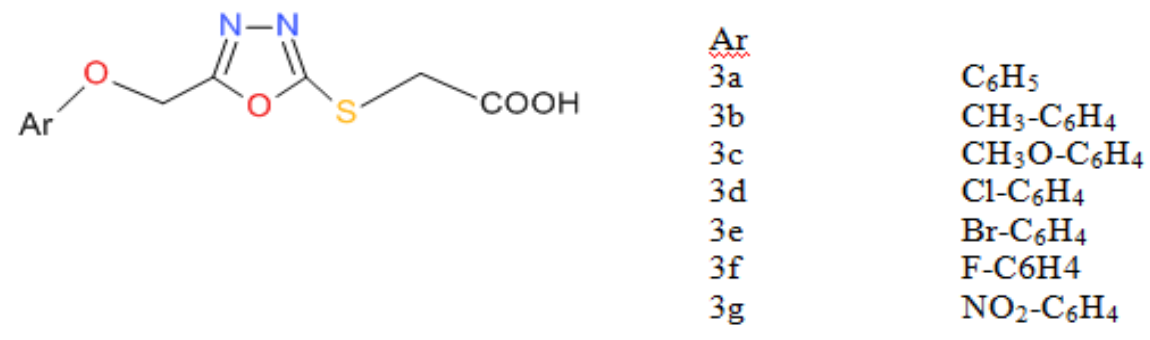

Fig. 1. The schematic structures of the 2-[5-(aryloxymethyl)-1, 3, 4oxadiazol-2-yl-sulfanyl] acetic acids derivatives

These compounds include 2-(5-(phenoxymethyl)-1,3,4-oxadiazol-2-ylsulfanyl) acetic acid 3a, 2-(5-((4-methylphenoxy) methyl)-1, 3, 4oxadiazol-2-ylsulfanyl) acetic acid 3b, 2-(5-((4methoxyphenoxy) methyl)-1, 3, 4-oxadiazol-2-yl sulfanyl) acetic acid 3c, 2-(5-((4-chlorophenoxy) methyl)-1,3,4-oxadiazol-2-ylsulfanyl) acetic acid 3d, 2-(5-((4-bromophenoxy)methyl)-1,3,4-oxadiazol-2-ylsulfanyl) acetic acid 3e, 2-(5-((4fluorophenoxy) methyl) -1,3,4-oxadiazol-2-yl sulfanyl) acetic acid $\mathbf{3 f}$ and 2-(5-((4-nitrophenoxy) methyl) -1,3,4-oxadiazol-2-ylsulfanyl) acetic acid 3g.

The major objectives of this research work are: to calculate molecular parameters using DFT method, to build up QSAR model that investigate the cytotoxicity of the molecules under study and to calculate the free energy of interactions (binding affinity, $\Delta \mathrm{G}$ ) of the ligand with the receptor in the binding site through molecular docking.

\section{Computational details}

Molecular descriptors and ligand optimization In present study, the optimization via quantum chemical method (DFT) of equilibrium geometries for seven molecular compounds was performed. Becke's gradients exchange correction (Becke, 1993) and the Lee, Yang, Parr correlation functional (i.e. B3LYP) (Lee et al 1988) are three parameters on which density functional theory method based on. Moreover, the exactness of density functional theory calculations is a function of basis set chosen. Thus, 6-31G** basis set was used for the optimization of the studied compounds so as to calculate descriptors which describe the bioactivity $\left(\mathrm{IC}_{50}\right)$ of the studied compounds. The optimizations of the compounds were achieved using quantum chemical software Spartan' 14 by wave function Inc (Spartan 14).

Furthermore, biological investigation on the molecules under study was carried out using the 
obtained molecular parameters to build quantitative structure-activity relation (QSAR) model (Pourbasheer et al 2009). This was achieved with the aid of multiple linear regression method which is a recurrent statistical process used in making QSAR model. More so, the developed QSAR model was validated by observing some geometric equations such as cross validation $\left(\mathrm{R}^{2}\right)$ and adjusted $\mathrm{R}^{2}$ (Equation 1 and 2 ).

$C V \cdot R^{2}=1-\frac{\sum(o b s-c a l)^{2}}{\sum(o b s-o b s)^{2}}$

The $\mathrm{R}^{2}$ adjusted could be calculated using equation (2)

$R_{a}^{2}=\frac{(N-I) \times R^{2}-P}{N-1-P}$

Moreover, the optimized molecular structures were also used for the study of docking to guesstimate binding affinity of the molecules to the $S$. aureus cell line, MTCC 121 receptor (PDB ID: 4b19).

\section{RESULTS AND DISCUSSION DFT calculation}

This research work through B3LYP/6-31G** level of theory brought about several descriptors i.e. HOMO and LOMO energies, solvation energy, polar surface area (PSA), dipole moment (DM), weight, Log P, Ovality and heteroatoms (average of electronic charges on all heteroatom in the compound) as shown in Table $\mathbf{1}$ and these were used to define the cytotoxicity of the compounds. Agreeing to the theory of frontier molecular orbital, the bioactivity was affected by the highest occupied molecular orbital energy and lowest unoccupied molecular orbital energy (very imperative descriptors) (Mu et al 2015; 2016). The calculated HOMO energy are $-6.46 \mathrm{eV}$, $-6.30 \mathrm{eV}, \quad-5.94 \mathrm{eV},-6.52 \mathrm{eV},-6.52 \mathrm{eV},-6.44 \mathrm{eV}$, $-6.14 \mathrm{eV}$ for 3a-g while calculated LUMO energy are $-0.85 \mathrm{eV}$ for $\mathbf{3 a},-0.82 \mathrm{eV}$ for $\mathbf{3 b},-0.78 \mathrm{eV}$ for 3c, $-0.99 \mathrm{eV}$ for $\mathbf{3 d},-1.03 \mathrm{eV}$ for $\mathbf{3 e},-0.90 \mathrm{eV}$ for $\mathbf{3 f}$, $-0.89 \mathrm{eV}$ for $3 \mathrm{~g}$.

Meanwhile, greater highest occupied molecular orbital energy shows the capability of a compound to bequeath electrons to adjoining receptor and equally, lesser lowest unoccupied molecular orbital energy enhances the knack of a molecule to admit electrons from the receptor.

Therefore, due to important role played by these two descriptors in the tie of molecules and enzymes, it is expected that the interactions that will occur be heightened, however, in this study, no fair correlation was established between the cytotoxicity of these compounds and the HOMO as well as the LUMO energies. More so, Figure 2 shows HOMO-LUMO overlay.

Table 1. The calculated molecular descriptors obtained from the studied compounds

\begin{tabular}{|c|c|c|c|c|c|c|c|c|c|}
\hline & HOMO & LUMO & BG & $\begin{array}{c}\text { DM } \\
\text { (Debye) }\end{array}$ & $\begin{array}{c}\text { SE } \\
\text { (Kj/mol) }\end{array}$ & CH & CP & GN & LOG P \\
\hline 3a & -6.46 & -0.85 & 5.61 & 4.54 & -48.49 & 2.80 & -3.66 & 2.38 & 3.20 \\
\hline 3b & -6.30 & -0.82 & 5.48 & 4.67 & -47.41 & 2.74 & -3.56 & 2.31 & 3.69 \\
\hline 3c & -5.94 & -0.78 & 5.16 & 3.90 & -52.66 & 2.58 & -3.36 & 2.19 & 3.07 \\
\hline 3d & -6.52 & -0.99 & 5.53 & 4.71 & -46.76 & 2.77 & -3.76 & 2.55 & 3.76 \\
\hline 3e & -6.52 & -1.03 & 5.49 & 4.65 & -48.21 & 2.75 & -3.76 & 2.57 & 4.03 \\
\hline 3f & -6.44 & -0.9 & 5.54 & 4.57 & -42.20 & 2.77 & -3.67 & 2.43 & 3.36 \\
\hline 3g & -6.14 & -0.89 & 5.25 & 4.68 & -55.09 & 2.62 & -3.52 & 2.35 & 2.84 \\
\hline & & & & & & \\
\hline
\end{tabular}




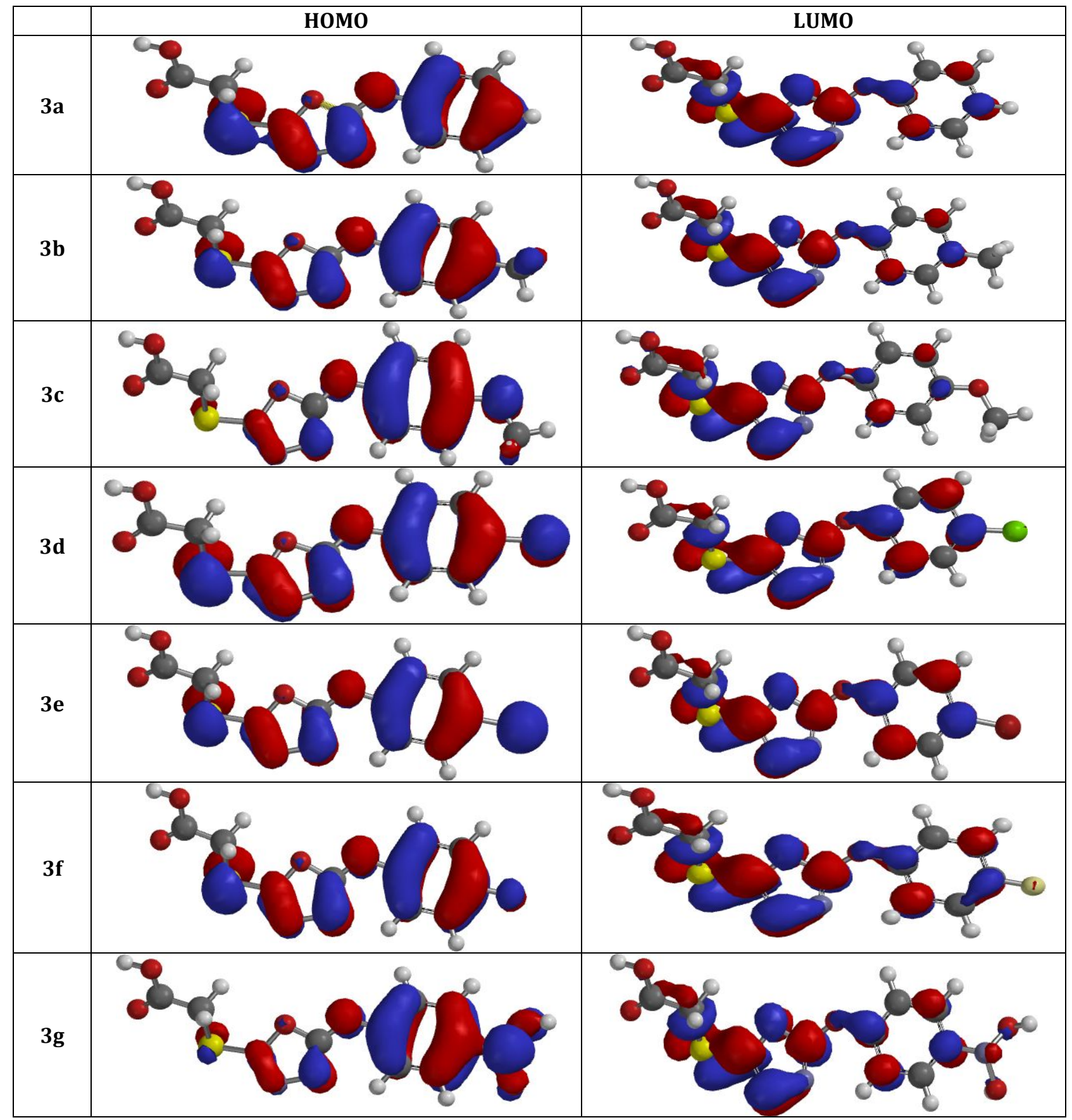

Fig. 2. HOMO-LUMO overlay

Moreover, the lower the band gap, the higher the capacity of a molecule to contribute electron(s) to the contiguous molecules. Therefore, the band-gap (LUMO energy - HOMO energy) which was calculated to be $5.61 \mathrm{eV}, 5.48 \mathrm{eV}, 5.16 \mathrm{eV}$, $5.53 \mathrm{eV}, 5.49 \mathrm{eV}, 5.54 \mathrm{eV}, 5.25 \mathrm{eV}$ for $3 \mathrm{a}-\mathrm{g}$ as revealed in Table 1 shows no correlation with the cytotoxicity of these compounds. Also, log P which was calculated to be 3.20, 3.69, 3.07, 3.76, $4.03,3.36,2.84$ for 3a-g reveal the ability of the compound to disband in lipophilic/non-aqueous solutions. Meanwhile, lipophilicity is dignified as the sharing of molecules between non-aqueous and aqueous phase and it exposes the biological activity of molecules (Abass et al 2011), so it was noted that, in oral absorption of ligand, delinquency may possibly occur if $\log \mathrm{P}$ is higher than 5 (Meanwell, 2011). Therefore, all the compounds in this study are effective in term of lipophilicity, since they are not greater than 5 . Furthermore, increased solvation energy could contribute to the drug opposition; thus, $\mathbf{3 c}$ and $\mathbf{3 g}$ were better in term of solvation energy. Also, it was reported that anomalous property of ligand is a function of huge value of dipole moment, so, 3a-g were appropriate in term 
dipole moment, since their dipole moment values are moderate. For polar surface area (PSA), all the compounds under study were orally active as it was noted that PSA should not surpass $120 \mathrm{~A}^{2}$ for drug that are orally energetic which were conveyed by trans cellular route (van de Waterbeemd et al 1998; Kelder et al 1999).

\section{QSAR studies}

The calculated parameters for seven molecular compounds functioned as independent variables, while the experimental inhibitory concentration (IC $\mathrm{I}_{50}, \mu \mathrm{M}$ ) against $S$. aureus cells line acted as dependent variable in building QSAR model via multiple linear regression (MLR).

In study of quantitative structural activities relation, the fitness and ability to predict could be used to appraise the developed QSAR model. So, equation 3 was obtained via the developed model which replicated the observed $\mathrm{IC}_{50}$ as shown in Figure 3 with fitting factor 0.995.

$$
\mathrm{IC}_{50}=0.299-0.008(\mathrm{HOMO})-0.009(\log \mathrm{P})
$$$$
-0.028(\mathrm{SE})-0.001(\mathrm{MW})-0.128(\mathrm{HBA})
$$

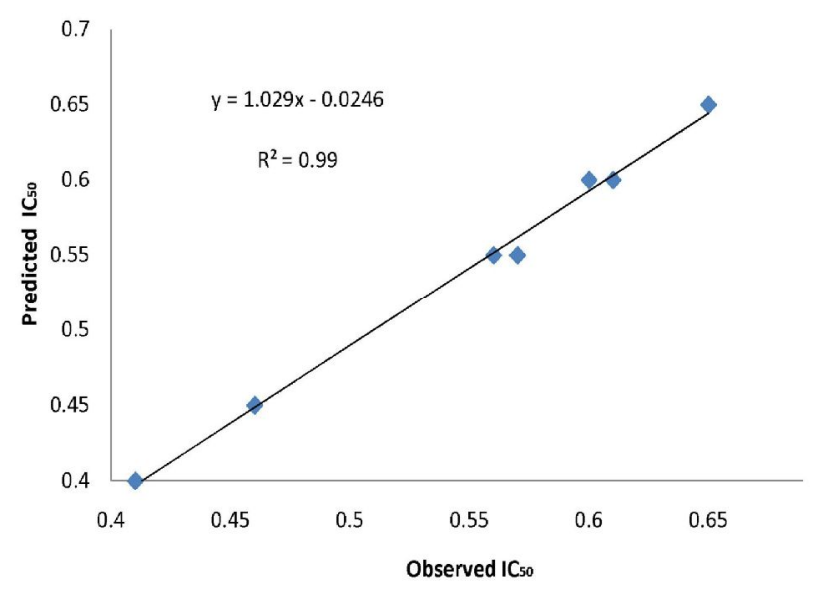

Fig. 3. Correlation between predicted and observed $\mathrm{IC}_{50}$

Therefore, the combination of HOMO, Log P, Solvation energy, Molecular weight and HBA defined the anti-S. aureus activity of the studied compounds. More so, the performance of QSAR model cannot be adequately authenticated by using only fitting value $\left(\mathrm{R}^{2}\right)$, therefore, it is necessary to validate QSAR model by using geometric equation (cross validation $\left(\mathrm{R}^{2}\right)$ and Adjusted $\mathrm{R}^{2}$ ) as shown in Table 2.

The obtained value for fitting factor $\left(R^{2}\right)(0.998)$ showed that it fitted well. Also, the cross validation value $\left(C V . R^{2}\right)(0.998)$ showed the steadfastness of the developed QSAR model, because the value obtained was higher than 0.5 (Standard) (Ponce et al 2004).

Table 2. Statistical parameters for validation of QSAR model

\begin{tabular}{|c|c|c|c|c|}
\hline $\mathbf{N}$ & $\mathbf{p}$ & $\mathbf{R}^{\mathbf{2}}$ & $\mathbf{C V}^{2} \mathbf{R}^{\mathbf{2}}$ & $\mathbf{R}^{\mathbf{2}}$ adj \\
\hline 7 & 5 & 0.998 & 0.998 & 0.988 \\
\hline
\end{tabular}

More so, the calculated value for adjusted $R^{2}$ (0.988) exposed that the QSAR model is prognostic since the calculated value is greater than 0.6 (Standard) (Table 2).

\section{Docking and scoring}

Docking study was executed on the studied compounds coupled with bacteria cell line (PDB ID: 4b19) (Sayed et al 2012) which was obtained from protein data bank.

The docking study was accomplished by using several softwares (Discovery studio, Autodock tool, Autodock vina and Pymol as post-dock software).

Nine conformations were obtained from the docking simulation of individual compound and highest free binding energy (i.e. more negative value) in each docking simulation was assumed to be most stable. The calculated binding energy for compound 3a-g were $-4.5 \mathrm{kcal} / \mathrm{mol},-5.0 \mathrm{kcal} /$ $\mathrm{mol}, \quad-4.7 \mathrm{kcal} / \mathrm{mol}, \quad-4.9 \mathrm{kcal} / \mathrm{mol},-4.9 \mathrm{kcal} / \mathrm{mol}$, $-4.8 \mathrm{kcal} / \mathrm{mol}$ and $-4.9 \mathrm{kcal} / \mathrm{mol}$ (Table 3 ).

In this study, several residues were involved in the interaction for the studied compound such as AGN-26, AGN-26, SER-25 and SER-25 with distance 2.8, 2.5, 2.5, 2.9 for 3a, LYS-30, THR-29, SER-25, SER-25 and ARG-26 with 2.4, 2.2, 3.1, $2.5,2.6$, and 2.7 as distance for compound $3 \mathbf{b}$, for compound 3c, ASN-28, SER-25, SER-25, ARG-26, ARG-26, ARG-26, ALA-18 with distance 3.1, 2.8, 2.4, 2.6, 2.9, 2.9, 3.1; SER-25, ARG-26, ARG-26, ARG-26, SER-25, LYS-30, THR-29, with 2.9, 2.8, 2.6, 2.8, 2.3, 2.3, 2.0 as distance for 3d, LYS-30, THR-29, SER-25, SER-25ARG-26, ARG-26, ARG26, with 2.3, 2.0, 2.9, 2.1, 2.7, 2.8, 2.8 for compound 3e, SER-25, SER-25, ARG-26, ARG-26, with 2.7, 2.6, 2.4, 2.8 for compound $\mathbf{3 f}$, and for compound 3g, ASN-28, SER-25, SER-25, ARG-26, ARG-26, ARG-26, ALA-18, ALA-18, with 3.3, 2.8, 2.3, 2.5, 2.8, 2.8, 3.1, 2.9. Therefore, compound 3b acted to be better in the interaction with $4 \mathrm{~b} 19$ receptor in term of binding energy as shown in Table 3 . The interaction between ligand and the receptor are shown in Figure 4. 
Table 3. Interactions between ligands and 4b19 receptor

\begin{tabular}{|c|c|c|c|}
\hline Compd & $\begin{array}{c}\text { Affinity } \\
\text { (kcal/mol) }\end{array}$ & $\begin{array}{l}\text { H-Bond Between protein residues in the binding } \\
\text { pocket and Drug }\end{array}$ & Distance \\
\hline $3 \mathbf{a}$ & -4.5 & $\begin{array}{c}\text { (i) AGN-26, LIG: } 0 \text { (ii) AGN-26, LIG:O (iii) SER-25, } \\
\text { LIG:O (iv) SER-25, LIG:O }\end{array}$ & $\begin{array}{l}\text { (i) } 2.8 \text { (ii) } 2.5 \text { (iii) } 2.5 \\
\text { (iv) } 2.9\end{array}$ \\
\hline $3 \mathbf{b}$ & -5.0 & $\begin{array}{l}\text { (i) LYS-30, LIG: O (ii) THR-29 LIG:O (iii) SER-25, LIG:O } \\
\text { (iv) SER-25, LIG: O (v) ARG-26 LIG:O (vI) ARG-26, LIG: } \\
0\end{array}$ & $\begin{array}{l}\text { (i) 2.4, (ii) 2.2, (iii) 3.1, } \\
\text { (iv) 2.5, (v) 2.6, (vi) } 2.7\end{array}$ \\
\hline $3 c$ & -4.7 & $\begin{array}{c}\text { (i) ASN-28, LIG: O (ii) SER-25, LIG:O (iii) SER-25, LIG:O } \\
\text { (iv) ARG-26 LIG:O (v) ARG-26 LIG:O (vi) ARG-26 LIG:O } \\
\text { (vii) ALA-18 LIG:O }\end{array}$ & $\begin{array}{l}\text { (i) } 3.1, \text { (ii) } 2.8, \text { (iii) } 2.4 \text {, } \\
\text { (iv) } 2.6 \text {, (v) } 2.9 \text {, (vi) } 2.9, \\
\text { (vii) } 3.1\end{array}$ \\
\hline $3 d$ & -4.9 & $\begin{array}{c}\text { (i) SER-25 LIG:O (ii) ARG-26 LIG:O(iii) ARG-26 LIG:N } \\
\text { (iv) ARG-26 LIG:N (v) SER-25 LIG: O (vi) LYS-30, LIG: O } \\
\text { (vii) THR-29, LIG:O }\end{array}$ & $\begin{array}{l}\text { (i) } 2.9 \text {, (ii) } 2.8 \text {, (iii) } 2.6 \text {, } \\
\text { (iv) } 2.8 \text {, (v) } 2.3 \text {, (vi) } 2.3 \text {, } \\
\text { (vii) } 2.0\end{array}$ \\
\hline $3 e$ & -4.9 & $\begin{array}{l}\text { (i) LYS-30, LIG:O (ii) THR-29, LIG:O (iii) SER-25, LIG:O } \\
\text { (iv) SER-25, LGI:O (v) ARG-26, LIG:O (vi) ARG-26, } \\
\text { LIG:O (vii) ARG-26, LIG:O }\end{array}$ & $\begin{array}{l}\text { (i) } 2.3 \text {, (ii) } 2.0 \text {, (iii) } 2.9, \\
\text { (iv) } 2.1 \text {, (v) } 2.7 \text {, (vi) } 2.8, \\
\text { (vii) } 2.8\end{array}$ \\
\hline $3 f$ & -4.8 & $\begin{array}{l}\text { (i) SER-25, LIG:O (ii) SER-25, LIG:O (iii) ARG-26, LIG:0 } \\
\text { (iv) ARG-26, LIG:0 }\end{array}$ & $\begin{array}{l}\text { (i) 2.7, (ii) 2.6, (iii) 2.4, } \\
\text { (iv) } 2.8\end{array}$ \\
\hline $3 g$ & -4.9 & $\begin{array}{l}\text { (i) ASN-28, LIG: O (ii) SER-25, LIG:O (iii) SER-25, LIG:O } \\
\text { (iv) ARG-26, LIG: O (v) ARG-26, LIG: O (vi) ARG-26, } \\
\text { LIG: O (vii) ALA-18, LIG: O (viii) ALA-18, LIG: H }\end{array}$ & $\begin{array}{l}\text { (i) } 3.3 \text {,(ii) } 2.8 \text {, (iii) } 2.3 \text {, } \\
\text { (iv) } 2.5, \text { (v) } 2.8 \text {, (vi) } 2.8 \text {, } \\
\text { (vii) } 3.1 \text {, (viii) } 2.9\end{array}$ \\
\hline
\end{tabular}

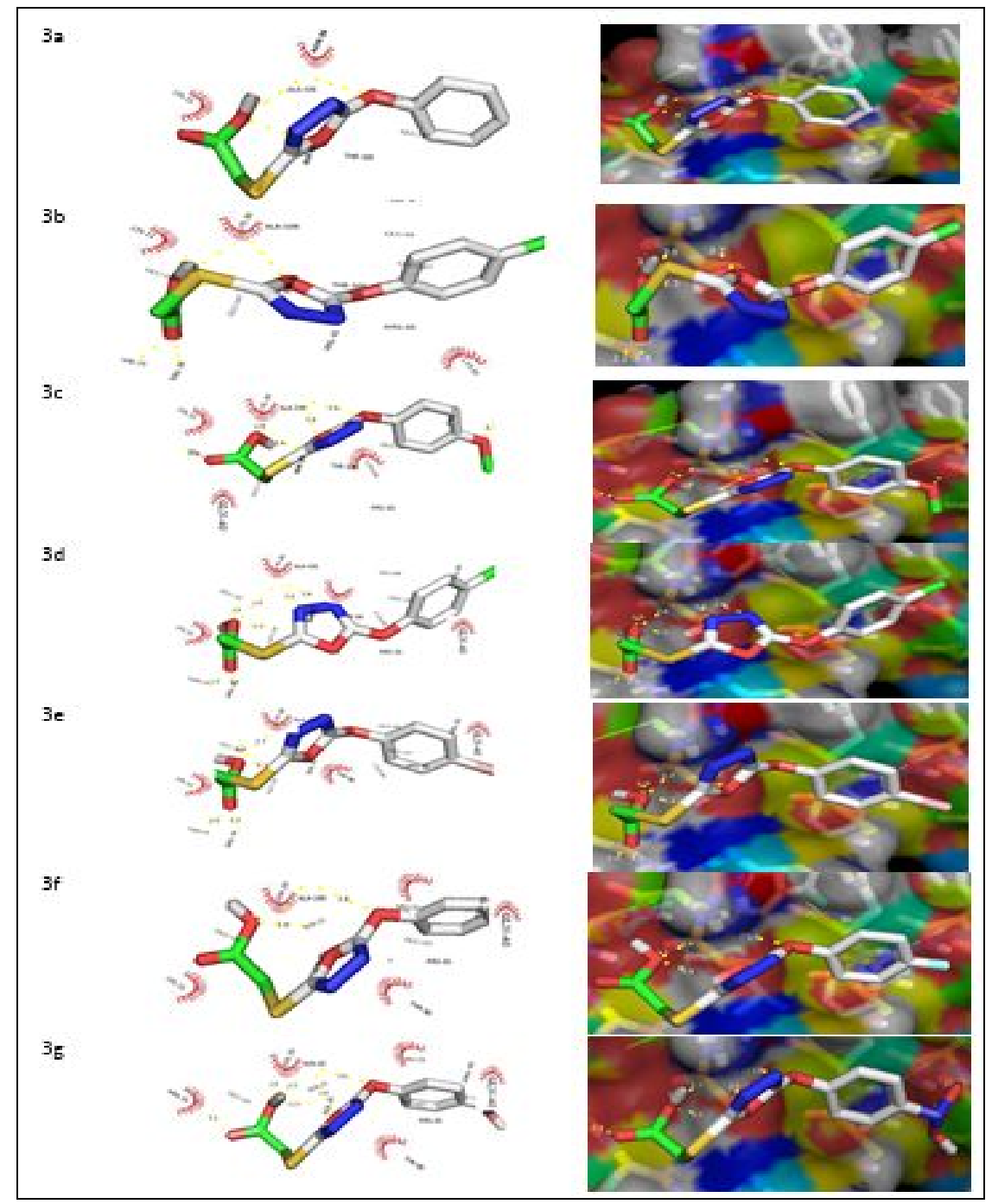

Fig. 4. Binding interaction of 3a-g with 4b19 


\section{CONCLUSION}

In this study, calculation of molecular parameters via DFT method was achieved as well as the anti-bacterial activity of 2-[5(aryloxymethyl)-1, 3, 4-oxadiazol-2-ylsulfanyl] acetic acids derivatives. The results of the QSAR study showed that certain parameters linked the

\section{REFERENCES}

Abass K, Reponen P, Mattila S, Pelkonen 0. Metabolism of $\alpha$ thujone in human hepatic preparations in vitro. Xenobiotica 2011;41(2):101-11. [DOI: 10.3109/0049825 4.2010.528066]

Arulmozhiraja S, Morita M. Structure-activity relationships for the toxicity of polychhorinated dibenzofurans: Approach through density functional theory-based descriptors. Chem. Res. Toxicol. 2004;17(3):348-56. [DOI: 10.1021/tx0300380]

Backhed F, Ley RE, Sonnenburg JL, Peterson DA, Gordon JI. Host-bacterial mutualism in the human intestine. Science 2005;307(5717):1915-20. [DOI: 10.1126/science.11048 16]

Balasubramanian R, Vijaya Gopal R. Design and in silico analysis of ring-A monosubstituted chalcones as potential anti-inflammatory agents. Bull. Pharm. Res. 2012;2(2): 70-7.

Brogden RN. Non-steroidal anti-inflammatory analgesics other than salicylates. Drugs 1986;32(4):27-45.

Dahiya R, Kaur R. Synthesis and biological screening of a novel series of 3,4,5-trisubstituted phenoxyacetic acid analogs. Aust. J. Basic Appl. Sci. 2007;1(4):525-32.

Dahiya R, Mourya R. Synthesis and antimicrobial screening of some novel halogenated phenoxyacetyl amino acid and peptides. Bull. Pharm. Res. 2012;2(2):56-65.

Dahiya R, Pathak D, Bhatt S. Synthesis and biological evaluation of a novel series of 2-(2'-isopropyl-5'methylphenoxy)acetyl amino acids and dipeptides. Bull. Chem. Soc. Ethiop. 2006a;20(2):235-45.

Dahiya R, Pathak D, Bhatt S. Synthesis and biological evaluation of a novel series of 2-(4-chloro-3methylphenoxy)acetyl amino acids and peptides. J. Saudi Chem. Soc. 2006b;10(1):165-76.

Dahiya R, Pathak D, Kaur R. Synthesis, characterization and biological screening of some new aryloxyacetic acid analogs. J. Indian Chem. Soc. 2008;85(7):754-8.

Dahl GE, Jaitly N, Salakhutdinov R. Multi-task neural networks for qsar predictions. arXiv:1406.1231, 2014;121.

Debenedetti P. Condensed Matter. J of Phy. 2003;15:1669.

Eroglu E, Turkmen H. A DFT-based quantum theoretic QSAR study of aromatic and heterocyclic sulfonamides as carbonic anhydrase inhibitors against isozyme, CA-II. J. Mol. Graph. Model. 2007;26(4):701-8. [DOI: 10.1016/j.j mgm.2007.03.015]

Fauci AS, Zerhouni EA. NIH response to open letter. Science 2005;308(5718):49. [DOI: 10.1126/science.308.5718.4 9b]

Gu C, Jiang X, Ju X, Gong X, Wang F, Bian Y, Sun C. QSARs for congener-specific toxicity of polyhalogenated dibenzo-pdioxins with DFT and WHIM theory. Ecotoxicol. Environ. Saf. 2009;72(1):60-70. [DOI: 10.1016/j.ecoenv.2008.04.0 03]

Hansch C. Quantitative approach to biochemical structureactivity relationships. Acc. Chem. Res. 1969;2(8):232-9. [DOI: 10.1021/ar50020a002] electronic properties of the studied compounds to their cytotoxicity, also the QSAR model replicated the observed bioactivities of these molecules against $4 \mathrm{~b} 19$. Moreover, the results obtained from docking predicted stable conformations of the ligands within the enzyme's active cavity.

Jacquemin D, Perpete EA, Ciofini I, Adamo C. Accurate simulation of optical properties in dyes. Acc. Chem. Res. 2009;42(2):326-34. [DOI: 10.1021/ar800163d]

Jain N, Saini D, Goyal R, Jain S. Synthesis and antibacterial screening of some 2-[5-(aryloxymethyl)-1, 3, 4-oxadiazol2-ylsulfanyl] acetic acids. Der Pharm. Chem. 2016;8(4):434-438.

Kaiser J. Microbiology: Détente declared on NIH biodefense funding. Science. 2005;308(5724):938. [DOI: 10.1126/ science.308.5724.938b]

Kelder J, Grootenhuis PD, Bayada DM, Delbressine LP, Ploemen JP. Polar molecular surface as a dominating determinant for oral absorption and brain penetration of drugs. Pharm. Res. 1999;16(10):1514-9. [DOI: 10.1023/a:1015040217741]

Kraka E, Cremer D. Computer design of anticancer drugs. A new enediyne warhead. J. Am. Chem Soc. 2000;122(34):8245-64. [DOI: 10.1021/ja001017k]

Lee C, Yang W, Parr RG. Development of the Colle-Salvetti correlation-energy formula into a functional of the electron density. Phys. Rev. B 1988;37(2):785-9. [DOI: 10.1103/PhysRevB.37.785]

Maloy S, Schaechter M. The era of microbiology: a golden phoenix. Int. Microbiol. 2006; 9(1):1-7.

Meanwell NA. Synopsis of some recent tactical application of bioisosteres in drug design. J. Med. Chem. 2011;54(8):2529-91. [DOI: 10.1021/jm1013693]

Morris GM, Lim-Wilby M. Molecular docking. Methods Mol. Biol. 2008;443:365-82. [DOI: 10.1007/978-1-59745-1772_19]

Mu J-X, Yang M-Y, Sun Z-H, Tan C-X, Weng J-Q, Wu H-K, Liu $\mathrm{X}-\mathrm{H}$. Synthesis, Crystal Structure and DFT Studies of 8chloro-3-((3-chlorobenzyl)thio)-[1,2,4]triazolo[4,3-

a]pyridine. Crystals 2015;5(4):491-500. [DOI: 10.3390/ cryst5040491]

Mu J-X, Zhai Z-W, Yang M-Y, Sun Z-H, Wu H-K, Liu X-H. Synthesis, Crystal Structure, DFT Study and Antifungal Activity of 4-(5-((4-Bromobenzyl)thio)-4-Phenyl-4H1,2,4-Triazol-3-yl)pyridine. Crystals 2016;6:4. [DOI: 10.33 90/cryst6010004]

Overbye KM, Barrett JF. Antibiotics: where did we go wrong? Drug Discov. Today 2005;10(1):45-52. [DOI: 10.1016/S1359-6446(04)03285-4]

Oyebamiji AK and Semire B. Studies of anti-hypertensive activity of 1, 4-dihydropyridine derivatives: combinations of DFT-QSAR and docking approaches. Bull. Pharm. Res. 2016a;6(3):105-13. [DOI: 10.21276/bpr.2016.6.3.4]

Oyebamiji AK, Semire B. DFT-QSAR model and docking studies of antiliver cancer (HEPG-2) activities of 1, 4diydropyridine based derivatives. Cancer Bio. 2016b;6(2):69-78. [DOI: 10.7537/marscbj06021610]

Oyebamiji KA, Semire B. Studies of 1, 4-dihydropyridine derivatives for anti-breast cancer (MCF-7) activities: Combinations of DFT-QSAR and docking methods. New York Science Journal. 2016;9(6):58-66. [DOI: 10.7537/ marsnys09061610] 
Ponce YM, Garit JA, Torrens F, Zaldivar VR, Castro EA. Atom, atom-type, and total linear indices of the "molecular pseudograph's atom adjacency matrix": Application to QSPR/QSAR studies of organic compounds. Molecules 2004;9(12):1100-23. [DOI: 10.3390/91201100]

Pourbasheer E, Riahi S, Ganjali MR, Norouzi P. Application of genetic algorithm-support vector machine for prediction of BKchannels activity. Eur. J. Med. Chem. 2009; 44(12):5023-8. [DOI: 10.1016/j.ejmech.2009.09.0 06]

Ramsden CA. Comprehensive Medicinal Chemistry: The Rational Design, Mechanistic Study, and Therapeutic Application of Chemical Compounds. Pergamon: Oxford, 1990.

Sayed N, Nonin-Lecomte S, Rety S, Felden B. Functional and structural insights of a Staphylococcus aureus apoptoticlike membrane peptide from a toxin-antitoxin module. J. Biol. Chem. 2012;287(52):43454-63. [DOI: 10.1074/jbc.M 112.402693]
Sharma V, Kumar V. Efficient way of drug designing: A comprehensive review on computational techniques. Bull. Pharm. Res. 2014;4(3):118-23.

Sharma V, Wakode SR, Lather V, Mathur R, Fernandes MX. Structure based rational drug design of selective phosphodiesterase-4 ligands as anti-inflammatory molecules. Bull. Pharm. Res. 2011;1(2):33-40.

Spartan 14 wave function Inc. Irvine, CA 92612, USA

van de Waterbeemd H, Camenisch G, Folkers G, Chretien JR, Raevsky OA. Estimation of blood-brain barrier crossing of drugs using molecular size and shape, and H-bonding descriptors. J. Drug Target. 1998;6(2):151-165. [DOI: 10.3109/10611869808997889]

Zhu M, Ge F, Zhu R, Wang X, Zheng X. A DFT-based QSAR study of the toxicity of quaternary ammonium compounds on Chlorella vulgaris. Chemosphere 2010;80(1):46-52. [DOI: 10.1016/j.chemosphere.2010.0 $3.044]$ 